\title{
Lipids and oocyte developmental competence: the role of fatty acids and $\beta$-oxidation
}

\author{
Kylie R Dunning, Darryl L Russell and Rebecca L Robker \\ School of Paediatrics and Reproductive Health, The Robinson Research Institute, University of Adelaide, \\ Medical School South Level 3, Adelaide, South Australia 5005, Australia \\ Correspondence should be addressed to R L Robker; Email: rebecca.robker@adelaide.edu.au
}

\begin{abstract}
Metabolism and ATP levels within the oocyte and adjacent cumulus cells are associated with quality of oocyte and optimal development of a healthy embryo. Lipid metabolism provides a potent source of energy and its importance during oocyte maturation is being increasingly recognised. The triglyceride and fatty acid composition of ovarian follicular fluid has been characterised for many species and is influenced by nutritional status (i.e. dietary fat, fasting, obesity and season) as well as lactation in cows. Lipid in oocytes is a primarily triglyceride of specific fatty acids which differ by species, stored in distinct droplet organelles that re-localise during oocyte maturation. The presence of lipids, particularly saturated vs unsaturated fatty acids, in in vitro maturation systems affects oocyte lipid content as well as developmental competence. Triglycerides are metabolised by lipases that have been localised to cumulus cells as well as oocytes. Fatty acids generated by lipolysis are further metabolised by $\beta$-oxidation in mitochondria for the production of ATP. $\beta$-oxidation is induced in cumulus-oocyte complexes (COCs) by the LH surge, and pharmacological inhibition of $\beta$-oxidation impairs oocyte maturation and embryo development. Promoting $\beta$-oxidation with L-carnitine improves embryo development in many species. Thus, fatty acid metabolism in the mammalian COC is regulated by maternal physiological and in vitro environmental conditions; and is important for oocyte developmental competence.
\end{abstract}

Reproduction (2014) 148 R15-R27

\section{Introduction}

Successful reproduction is dependent on the ovulation of an oocyte capable of undergoing fertilisation and subsequent embryo and foetal development, and requires the co-ordinated and stepwise growth and maturation of the oocyte and its companion somatic cells known collectively as the ovarian follicle. Ovarian follicles grow from the dormant primordial stage in which the oocyte is surrounded by a single layer of granulosa cells to a preovulatory stage follicle. By this stage, the fully grown oocyte has amassed nutrient stores, mRNA, proteins and organelles, including large numbers of mitochondria, and is surrounded by specialised cumulus cells, a fluid-filled antral cavity and a stratified epithelial layer of granulosa cells. Ovulation of the cumulus-oocyte complex (or COC) and the final stages of oocyte maturation are initiated by a surge of luteinising hormone (LH), which signals to the oocyte via the granulosa and cumulus cells to resume meiosis and complete nuclear maturation to the metaphase II (MII) stage of meiosis in preparation for fertilisation. These rapid and tightly synchronised events, which include granulosa cell proliferation, cumulus cell matrix production and chromosome segregation, are energy-consuming processes and require adequate generation of ATP from cellular energy stores.

The in vitro maturation of oocytes (IVM) involves removal of the COC from the antral follicle before the $\mathrm{LH}$ surge and stimulation of the final stages of maturation in vitro, i.e. in the absence of the in vivo follicular signals. Oocytes matured by IVM are however less likely to develop to the blastocyst stage (Rizos et al. 2002, Gilchrist \& Thompson 2007) and result in higher rates of miscarriage compared with oocytes that mature in follicles in vivo (Buckett et al. 2008). The causal mechanisms responsible for this poor oocyte quality following IVM are not clear; however, oocyte developmental competence is associated with the metabolism and metabolic rate of the oocyte and its surrounding cumulus cells (Biggers et al. 1967, Downs 1995, Sugiura \& Eppig 2005, Preis et al. 2007, Thompson et al. 2007). Adequate levels of intracellular ATP are also required for optimal oocyte developmental potential (Van Blerkom et al. 1995) and therefore energy substrate supply to the COC via the follicular fluid or culture medium during in vivo maturation or IVM, respectively, is likely to affect oocyte quality.

Lipids are hydrophobic or amphipathic molecules with diverse biological roles that include being a rich 
source of energy, cell signalling mediators and the foundation of plasma and organelle membranes. Fatty acids are a class of lipid and function as structural components of membranes, precursors for prostaglandin synthesis and to anchor proteins to cell membranes. Fatty acids are also stored intracellularly as triacylglycerides within lipid droplets, providing a potent source of energy upon demand; for instance, oxidation of the fatty acid palmitate can generate 106 ATP molecules compared with glucose oxidation which yields $\sim 30$ ATP molecules.

Important roles for fatty acids in the promotion of embryo development have been clearly demonstrated and comprehensively reviewed (McKeegan \& Sturmey 2011); however, accumulating evidence indicates that the metabolism of lipids by $\beta$-oxidation in the COC before fertilisation also influences subsequent oocyte developmental potential. Oocytes in particular but also cumulus cells are well known to contain lipid droplets, but how these are utilised during oocyte maturation is only just emerging. Similarly, although lipid utilisation by oocytes has been demonstrated primarily by indirect methods (reviewed in Sturmey et al. (2009)), $\beta$-oxidation within the whole COC has been directly documented more recently and appears to be occurring in large part in cumulus cells. Understanding these pre-conceptional roles of fatty acids in both cumulus cells and oocytes is essential in order to understand how physiological alterations in follicular lipids, as well as the supply of lipids as substrates for metabolism during IVM, impacts the earliest stages of embryo development.

\section{Fatty acid supply to the COC}

\section{Lipid composition of ovarian follicular fluid and relationship to serum}

Free fatty acids (or non-esterified fatty acids (NEFA)) are attached to serum albumin which acts as a carrier protein rendering the insoluble fatty acid suitable for transport through the circulation to tissues. However, the majority of circulating fatty acids are in the form of carboxylic acid derivatives including esters or amides. Fatty acids are also stored as triacylglycerol molecules, or triglycerides, in which three fatty acid molecules are attached to a glycerol backbone; and these are carried throughout the blood in lipoprotein particles, i.e. HDLs, LDLs and VLDLs. Triacylglycerols and fatty acids are present in the follicular fluid of numerous species and there is emerging interest in understanding how these substrates are ultimately utilised by ovarian somatic cells and oocytes for energy production. Analyses of lipoproteins in human follicular fluid in several studies corroborate that HDLs but little or no LDL or VLDL are present (Simpson et al. 1980, Perret et al. 1985, Volpe et al. 1991, Jaspard et al. 1997). Follicular fluid HDL cholesterol is positively correlated with serum HDL cholesterol
(Gautier et al. 2010, Valckx et al. 2012), indicating that HDL particles are serum derived and passively equilibrated; however, there is no similar correlation for VLDL cholesterol in follicular fluid and serum (Gautier et al. 2010). Thus, it is generally accepted that in mammals $\mathrm{HDL}$ is the sole lipoprotein present in follicular fluid due to the porosity of the follicle basement membrane which is permeable to serum proteins up to $300 \mathrm{kDa}$ in size (Shalgi et al. 1973), thus excluding LDL and VLDL. Interestingly, although LDL and/or VLDL are detected in follicular fluid of some women (Von Wald et al. 2010) and it is also reported that human granulosa-lutein cells express lipoprotein marker ApoB-100 and assemble and secrete in vitro-native VLDL particles similar to those in serum, except with slightly higher triglyceride content and less cholesterol (Gautier et al. 2010). Thus, LDL and VLDL particles detected in follicular fluid may in fact be generated by ovarian cells.

It is well understood that HDL particles have important functions in granulosa and theca cell steroidogenesis, serving as the predominant source of cholesterol (Azhar et al. 1998, Hughes et al. 2011); yet studies examining the effects of lipoproteins on oocyte developmental competence are contradictory. Studies in the mouse demonstrate the importance of HDL integrity for oocyte competence; as knockout mice lacking the HDL receptor scavenger receptor class $B$, member 1 (SRBI) are infertile due to fertilised oocytes arresting before the morula stage (Miettinen et al. 2001). These mice have abnormally large circulating HDL particles and, interestingly, restoration of SRBI expression in the liver alone is sufficient to normalise HDL particle size and restore fertility (Yesilaltay et al. 2006). Increased HDL in human follicular fluid was associated with low embryo fragmentation (Browne et al. 2008, 2009), suggesting that HDL components play a cytoprotective role for the oocyte. Similarly, high ApoB in human follicular fluid is associated with better quality embryos and higher pregnancy rates (Gautier et al. 2010). However, two recent studies have shown that increased HDL and ApoAI levels were associated with failure of oocytes to cleave and decreased the numbers of good quality embryos (Valckx et al. 2012, Wallace et al. 2012). Furthermore, it is unclear whether lipoproteins found in follicular fluid influence oocyte quality via their ability to deliver lipid substrates such as triacylglycerol or whether other components of these particles, namely the surrounding apolipoproteins, which are known to have scavenging properties, protect cells from oxidative stress.

Numerous studies have compared triacylglycerol and free fatty acid levels between serum and follicular fluid. In dairy cows, follicular fluid triacylglycerol and free fatty acid (i.e. NEFA) levels were lower than but significantly correlated with those in serum (Leroy et al. 2004a,b). Linoleic, palmitic and oleic acid (see Table 1) predominate in the total fatty acid fraction of bovine follicular fluid (Homa \& Brown 1992, 
Table 1 The common name and structure of fatty acids.

\begin{tabular}{|c|c|c|c|}
\hline $\begin{array}{l}\text { Common } \\
\text { name }\end{array}$ & Structure & & Saturation \\
\hline Myristic acid & 14:0 & & Saturated \\
\hline Palmitic acid & $16: 0$ & & Saturated \\
\hline Stearic acid & 18:0 & & Saturated \\
\hline Oleic acid & $18: 1(9)$ & & Monounsaturated \\
\hline Linoleic acid & $18: 2(9,12)$ & $n-6$ & Polyunsaturated (PUFA) \\
\hline $\begin{array}{l}\alpha \text {-linolenic } \\
\text { acid }\end{array}$ & $18: 3(9,12,15)$ & $n-3$ & Polyunsaturated (PUFA) \\
\hline $\begin{array}{l}\text { Arachidonic } \\
\text { acid }\end{array}$ & $20: 4(5,8,1,14)$ & $n-6$ & Polyunsaturated (PUFA) \\
\hline Adrenic acid & $22: 4(7,10,13,16)$ & $n-6$ & Polyunsaturated (PUFA) \\
\hline
\end{tabular}

These varying structures play important biological roles, but for the purpose of energy production via oxidation, longer saturated fatty acids yield more energy than shorter or unsaturated fatty acids.

Tsujii et al. 2001). Oleic, palmitic and stearic acid were the most prevalent free fatty acids in follicular fluid from lactating cows, and were $\sim 40 \%$ of the levels in serum (Leroy et al. 2005a). Free fatty acid levels may be related to follicle maturation, as follicles with higher oestrogen: progesterone $\left(E_{2}: P_{4}\right)$ ratio have more palmitic and oleic acids and less stearic and linoleic acids (Renaville et al. 2010). In human follicular fluid, recent analyses have demonstrated that most serum metabolites including triacylglycerol and free fatty acids are reflected in follicular fluid, but at lower levels (Valckx et al. 2012). Oleic, linoleic and palmitic acids are the most prevalent free fatty acids in human follicular fluid and exhibit weak but significant correlations with levels in serum (Jungheim et al. 2011).

Thus, there is extensive information about the prevalence of lipoproteins, triacylglycerol and free fatty acids in the microenvironment of the COC, namely the follicular fluid. However, whether lipoproteins act as a major delivery system of lipids or whether other specific lipid transport systems are required in cumulus cells and/or the oocyte is not known. Furthermore, although the fatty acid composition of follicular fluid of many species has been characterised, it is unclear whether or to what extent the metabolism of follicular fluid fatty acids provides ATP to the cumulus cells and/or oocyte. Importantly, no studies to date have demonstrated a correlation of any specific follicular fluid fatty acids with fertility outcomes.

\section{Lipid droplets in oocytes}

Oocytes are renowned as large cells containing lipid stores and numerous studies have observed differences in the darkness of the oocyte cytoplasm, even in oocytes from the same ovary, and deemed it lipid. Bovine oocytes classified into different 'darkness categories' were found to have differences in cleavage and blastocyst development rates in vitro (Jeong et al. 2009). Comparison of bovine oocytes with light homogeneous cytoplasm and those with course dark cytoplasm found that palmitic acid was equally prevalent in both types, but that light oocytes contained a higher percentage of oleic and linoleic (18:2) fatty acids, while the darker oocytes had more saturated stearic acid (Kim et al. 2001). Thus the optical density of the ooplasm may indeed reflect its lipid, i.e. fatty acid, content, and if so, suggests that lipid content contributes to oocyte developmental competence.

Using a variety of techniques, many studies have quantified lipids in oocytes and determined that triacylglycerol is the major constituent (reviewed in Sturmey et al. (2009)). An early study determined that 'ova' isolated from the oviducts of mated mice contain $3.25 \mathrm{ng}$ of lipid or $12.5 \%$ of the dry mass based on sample weight before and after chloroform extraction (Loewenstein \& Cohen 1964). Since then lipid storage in intracellular droplets has been identified by electron microscopy of oocytes from many species, including rabbit (Zamboni \& Mastroianni 1966), cat (Martins et al. 2009), pig (Kikuchi et al. 2002) and cow (Kruip et al. 1983), with the lipid droplets often associated with mitochondria. Lipophilic Nile red dye is also commonly used to visualise lipid in oocytes; oocytes that have darker cytoplasm have greater Nile red staining (Leroy et al. 2005b). Decomposition of Nile red spectra was used to quantify triacylglycerol, phospholipid and cholesterol in oocytes and embryos (Romek et al. 2011); Nile Red staining of porcine oocytes followed by florescence resonance energy transfer was used to demonstrate that lipid droplets and mitochondria are within $\sim 10 \mathrm{~nm}$ of each other (Sturmey et al. 2006). BODIPY $493 / 503$ is a neutral lipid dye that has more recently been used to detect lipid droplets in oocytes and demonstrate they are bounded by the lipid droplet protein ADRP in both mouse and bovine (Yang et al. 2010, Aardema et al. 2011). Examination of lipid droplets in an individual mouse oocytes by matrixassisted laser desorption/ionisation mass spectrometry (MALDI-MS) (Ferreira et al. 2010) and syncotron Fourier transform-infrared (FT-IR) and Raman microspectroscopy demonstrated that the molecular composition of the lipid deposits exhibits spatial organisation within the droplet (Wood et al. 2008) and that mature oocytes which have high developmental competence have a distinct lipid profile compared with oocytes with immature chromatin structures that are unable to complete meiosis and form blastocysts (Ami et al. 2011). Overall, however, our understanding of the mechanisms that control lipid deposition in oocytes is in its infancy.

Interestingly, oocytes of different species exhibit marked variations in lipid content. We have used BODIPY 493/503 neutral lipid stain to illustrate these differences in oocyte lipid content between several species: mouse, cow, sheep, pig and humans (Fig. 1). Pig oocytes are known to be lipid laden, with the majority stored as neutral lipids, mainly triacylglycerol 

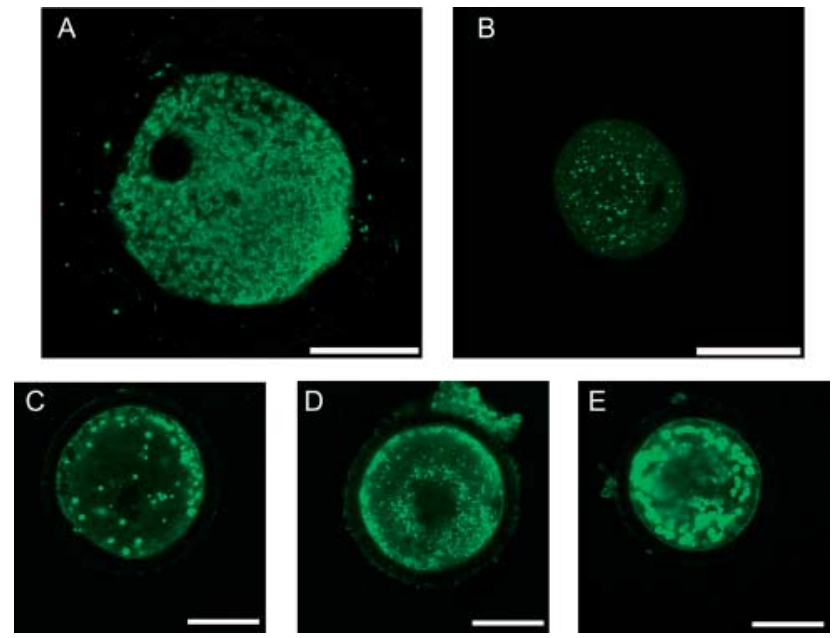

Figure 1 Lipid droplet localisation in mammalian oocytes. Images of immature oocytes from humans (A), mouse (B), sheep (C), cow (D) and pig (E) stained with BODIPY 493/503 neutral lipid dye. All procedures were carried out in serum-free polyvinylpyrrolidone-(PVP; $0.2 \% \mathrm{w} / \mathrm{v}$ )containing medium or PBS. Cumulus-oocyte complexes were denuded and oocytes fixed in $4 \%$ paraformaldehyde. Oocytes were permeabilised for $30 \mathrm{~min}$ in $0.1 \%(\mathrm{w} / \mathrm{v})$ saponin/0.1 M glycine in PBS and intracellular neutral lipid stained with BODIPY 493/503

(Molecular Probes) $1 \mu \mathrm{g} / \mathrm{ml}$ in PBS for $1 \mathrm{~h}$ in the dark. Oocytes were imaged by confocal microscopy (FluoView FV10i; Olympus), using fixed, predetermined magnification and exposure settings.

Scale bar $=60 \mu \mathrm{m}$. The human oocyte was obtained during routine IVF procedures, and fixed and stained following its failure to fertilise.

Diffuse staining and morphology is likely due to the $24 \mathrm{~h}$ of in vitro culture. Mouse oocyte was collected $48 \mathrm{~h}$ post-eCG (5 IU) stimulation. Cow, sheep and pig oocytes for staining were collected from abattoir material.

and cholesterol, which were threefold more abundant than phospholipids (Homa et al. 1986). Analysis of pig oocytes revealed that palmitic acid followed by oleic acid were the most abundant fatty acids, in terms of both total lipids and neutral lipids; however, n-6 PUFAs such as linoleic, arachidonic and adrenic acids also represent a significant proportion of fatty acids (Homa et al. 1986). Comparison of cow, pig and sheep oocytes revealed that pig had the most triglyceride with $\sim 74$ ng per oocyte, about three times more than both cow and sheep (McEvoy et al. 2000). Pig also had the most total fatty acids ( $\sim 160$ ng per oocyte), which was 2.5 -fold more than cow and 1.8 times more than sheep. Palmitic, stearic and oleic acids were the most abundant in oocytes of cow, pig and sheep, but pig had higher palmitic than oleic acids whereas cow and sheep had greater relative oleic acid. Although oocyte size was not taken into consideration, Nile red staining has also been used to show that porcine oocytes have 2.4 times more lipid than bovine oocytes which in turn have 2.8 -fold more than mouse oocytes (Genicot et al. 2005).

There has been relatively little analysis of lipid content of human oocytes. One study analysed lipid content of fertilisation-failed human oocytes pooled into groups of ten and found that the major fatty acids were stearic (38\% of total fatty acids), palmitic $(33 \%)$, oleic $(10 \%)$, myristic (4\%) and linoleic (4\%) acids. Saturated fatty acids represented $79 \%$, mono-unsaturated were $14 \%$, n-6 PUFA 5\% and n-3 PUFA 1\% (Matorras et al. 1998). This study indicates that the types of lipids present in human oocytes are relatively similar to those in the oocytes of other species. Interestingly, the fatty acid composition of the human oocytes was very different to that of comparable female adipose tissue which was just $27 \%$ saturated fatty acid (Matorras et al. 1998). Similarly, bovine oocytes (Wonnacott et al. 2010) and whole COCs (Adamiak et al. 2006) are enriched in saturated fatty acids compared with granulosa cells and plasma from the same animals, suggesting selective uptake and/or de novo fatty acid synthesis in oocytes as well as specific energy storage and metabolism needs.

During the course of oocyte maturation, the intracellular lipid stores undergo dramatic changes. In pig oocytes, lipid droplets exhibit a pronounced peripheral distribution pattern following maturation in vitro (Sturmey et al. 2006). Bovine oocytes matured in vitro exhibit a small but significant increase in the number of lipid droplets compared with germinal vesicle stage (GV) oocytes (Aardema et al. 2011). In mouse oocytes, lipid droplets undergo structural reorganisation, aggregating centrally during the course of maturation in vitro (Yang et al. 2010) or in vivo (Wood et al. 2008, Wu et al. 2010).

Importantly, oocyte lipid content can be altered by the environment in which the oocyte matures, particularly by serum and lipid supplements used for IVM. Bovine oocytes matured in 10\% FCS have more triacylglycerol and more cholesterol than those matured in serum-free conditions (Kim et al. 2001). Similarly, mouse COC matured in 5\% serum contain more neutral lipid in the oocytes than those matured in fatty acid-free media (Yang et al. 2010). From these studies it is concluded that the increased oocyte lipids in response to serum is due to simple diffusion. However, serum also contains a number of growth factors, cytokines and metabolites, which could increase intracellular lipid via inducing transporter-mediated fatty acid uptake and/or triglyceride biosynthesis. Furthermore, these experiments utilised whole COCs and little is known about how maturation in different in vitro environments impacts cumulus cell lipid content. It is also likely that cumulus cells directly influence oocyte triacylglycerol and/or fatty acid deposition, similar to their role in controlling oocyte cholesterol content (Su et al. 2008). In support of this, IVM of bovine oocytes in the absence of cumulus cells results in decreased intracellular lipid stores (Auclair et al. 2013), suggesting that in the absence of cumulus cell-supplied metabolites the oocyte has less capacity for lipid storage or may more heavily utilise intracellular lipid stores for its energy requirements.

There is surprisingly little direct evidence for how oocyte lipid content might influence developmental 
competence under normal physiological circumstances. There are examples of mouse oocytes, with poor developmental competence having more lipid droplets compared with developmentally competent oocytes; however, the poor oocytes also exhibit other fundamental cytoplasmic differences (Kim et al. 2001, Monti et al. 2013). Thus, further work is clearly needed to understand whether oocyte (or cumulus cell) lipid content may indeed be a biomarker of competence and, more importantly, how physiological or in vitro alterations to COC lipid content may impact embryo development. It is notable that palmitic, stearic, oleic and linoleic fatty acids are consistently the most prevalent in oocytes across species, with saturated fatty acids generally accounting for the vast majority of stores. The variations in oocyte lipid content across different species are perhaps indicative of distinct physiological requirements during early embryo development. Certainly, the long-chain fatty acids prevalent in mammalian oocytes are energy rich and differing levels of unsaturated fatty acids, such as oleic acid, could influence cellular membrane fluidity. This is illustrated by the fact that lipid content influences oocyte viability following cryopreservation by changing membrane integrity (reviewed in Zhang et al. (2012)).

\section{Influences of physiological conditions on follicular fluid and oocyte lipid content}

\section{Diet and body composition}

As circulating lipid metabolites are often similarly reflected in follicular fluid, it stands to reason that physiological conditions in which serum lipids are altered would affect lipid levels in the follicle and oocyte. Indeed, there are many examples of diet and body composition influencing the lipid content of follicular fluid and ovarian cells, including oocytes. For instance, beef heifers given dietary fish oil supplementation for 46 days exhibited dose-dependent alterations in specific n-3 and n- 6 fatty acids in follicular fluid (Childs et al. 2008). Ewes fed a diet supplemented with fish oil for 13 weeks had significantly more 18:2 and 22:6 in follicular fluid and more 18:2, 18:3, 20:4, 22:4 and 22:6 in cumulus cells (Zeron et al. 2002). There were no differences detected in oocyte lipid content, but oocytes from animals that fed fish oil had better morphology and improved membrane integrity in response to chilling (Zeron et al. 2002). Ewes fed a combination of fish and vegetable oils containing $n-3$ and n-6 PUFAs had increased $n-3$ and n-6 fatty acids in granulosa cells and oocytes respectively (Wonnacott et al. 2010). Heifers with moderate body condition score had less fatty acids in aspirated COCs than heifers with low body condition score; and the inclusion of a lipid supplement in the diet for 35 days increased the total fatty acid content of whole COCs (Adamiak et al. 2006). In contrast to experiments that increased or altered fat in the diet, cows that were fasted for 4 days also exhibited increased NEFA in both plasma and follicular fluid (Jorritsma et al. 2003, Aardema et al. 2013). Interestingly, there are also seasonal changes in the fatty acid composition of bovine ovarian follicles. Namely, the levels of all fatty acids analysed were increased in follicular fluid in winter compared with summer (Zeron et al. 2001). Furthermore, granulosa cells and oocytes isolated in summer had a higher percentage of saturated membrane phospholipids, particularly palmitic acid, while in winter they had a greater percentage of unsaturated phospholipids, particularly 16:1, 18:1, 18:2 (Zeron et al. 2001). These differences significantly alter the biophysical behaviour of the oocytes, but it is unclear how this may be related to seasonal differences in diet and the observed better developmental competence of oocytes isolated in winter.

In addition to the large literature on ruminants, studies on mice also demonstrate that diets rich in specific lipids are associated with changes in the lipid content of ovarian cells. Mice fed a high n-3 diet for 4 weeks had increased n-3 fatty acid content in the ovary and this was associated with altered oocyte mitochondrial distribution, increased ROS levels and poorer embryo morphology and development into blastocyst following fertilisation in vivo (Wakefield et al. 2008). Mice fed a diet high in saturated fat for 4 weeks exhibited marked lipid accumulation in both oocytes and cumulus cells, as well as evidence of lipotoxicity responses, which were associated with impaired fertilisation in vivo (Wu et al. 2010). Overall, these studies on animals show that dietary lipids can alter the fatty acid composition of not only blood and follicular fluid but also cumulus cells and oocytes. How these changes relate to the observed changes in conception rates and fertility in response to different dietary paradigms is an important area of investigation. It is likely that alterations in cellular fatty acid levels cause structural changes in membranes that influence fluidity. Furthermore, exposure to excessive dietary saturated fat is associated with oocyte mitochondrial damage, which is in turn related to induction of oxidative stress (Igosheva et al. 2010) and endoplasmic reticulum (ER) stress (Wu et al. 2012); however, whether the alterations in mitochondrial activity in these cases change ATP generation has not been definitively shown.

Very little is known about how dietary lipids in humans may affect follicular fluid or ovarian cell lipid composition; however, differences in body composition are associated with distinct alterations. In women attending a fertility clinic, increased BMI $\left(\mathrm{kg} / \mathrm{m}^{2}\right)$ was associated with increased levels of follicular fluid triglyceride (Robker et al. 2009) that mirrors changes in blood (Valckx et al. 2012). Free fatty acids in follicular fluid do not seem to be tightly correlated with BMI (Jungheim et al. 2011, Valckx et al. 2012), yet elevated follicular free fatty acids have been associated with poor cumulus-oocyte morphology (Jungheim et al. 2011), 
providing evidence that alterations in ovarian lipid profile can impact the human COC during its maturation. Furthermore, mouse oocytes exposed to human follicular fluid that is high in free fatty acids and triglycerides during maturation had increased oocyte lipid content and impaired nuclear maturation (Yang et al. 2010). Thus, it is becoming increasingly important to better understand how the follicular environment is affected by specific metabolic conditions; not only obesity but also polycystic ovary syndrome (PCOS) which is also associated with a more atherogenic lipid profile, i.e. higher circulating triglycerides, cholesterol and LDL and lower HDL (Valkenburg et al. 2008).

\section{Lactation in dairy cows}

With the onset of lactation, dairy cows experience systemic negative energy balance that is associated with dramatic elevations in circulating lipids as well as follicular fluid lipid levels and this is emerging as a significant negative influence on their fertility (Leroy et al. $2008 a, b)$. The follicular fluid of both heifers and lactating cows was shown to contain primarily linoleic, oleic, stearic and palmitic acids: however, compared with heifers, the cows had higher levels of at least 24 different fatty acids in follicular fluid, particularly palmitic acid and stearic acid and lower levels of docosahexaeonic acid (Bender et al. 2010). In dairy cows, circulating triglyceride levels decrease at parturition, while NEFA levels increase dramatically, relative changes that are also reflected in the follicular fluid (Leroy et al. 2004b). By day 44 post-partum, follicular fluid NEFA levels have increased to match that in serum, yet follicular fluid is selectively enriched with palmitic, oleic and linoleic fatty acids (Leroy et al. 2005a). These studies highlight that serum NEFA levels are dynamic, increasing dramatically at parturition; and that during lactation follicular fluid NEFA also increase but display a distinct fatty acid profile compared with serum (Leroy et al. 2005a, Bender et al. 2010). Oocytes of repeat breeder dairy cows were also shown to contain significantly more lipid than oocytes from virgin heifers, even though the COCs isolated from both types of animals were classified as normal good quality (Awasthi et al. 2010). Importantly, however, the dairy cows in this study were also significantly older and had a higher body condition score which could also affect oocyte lipid content.

There is of interest in using different dietary supplements, particularly those enriched with specific fatty acids to improve fertility in dairy cows (Leroy et al. 2011). For instance, in addition to studies described earlier, dairy cows fed a diet high in linoleic acid had an increased proportion of this fatty acid in follicular fluid and COCs, while cows fed a diet high in a-linolenic acid had an increased proportion of a-linolenic acid in follicular fluid, granulosa cells and aspirated COCs, as well as improved cleavage rates following IVF
(Zachut et al. 2010). Thus dietary fat supplementation, which is known to influence reproductive performance in ruminants, particularly during lactation, may do so by influencing follicular fluid and cellular lipid levels.

\section{Effects of lipid supplementation during oocyte IVM}

In vitro experiments examining the direct effects of specific lipids on oocytes and early embryos are beginning to shed light on the mechanisms by which physiological conditions that alter circulating lipids influence fertility. In particular, a large body of work conducted in bovine oocytes is elucidating the mechanisms by which elevations in specific fatty acids contributes to reduced conception rates in dairy cows. These experiments also emphasise how lipid substrates in various in vitro oocyte maturation culture systems might differentially affect oocyte maturation and embryo development.

Although increased body fat is associated with higher oocyte and neutral lipid content, there are conflicting reports about whether oocyte IVM in the presence of high lipid directly impacts oocyte lipid content. Mouse COC exposed to follicular fluid that was high in both triglycerides and free fatty acids had increased oocyte neutral lipid content at the end of IVM compared with those matured in lipid-poor follicular fluid (Yang et al. 2012). In contrast, treatment of bovine oocytes with either stearic acid or palmitic acid during maturation did not increase oocyte lipid content (Leroy et al. 2005a). A more recent study has shown that bovine COCs exposed to palmitic acid and stearic acid during maturation had decreased oocyte lipid droplet size and number compared with controls; and also that oleic acid reversed these effects and at highest concentrations even promoted oocyte lipid storage, i.e. increased oocyte droplet size and number (Aardema et al. 2011). However, when bovine COCs were treated with a mixture of these three NEFAs (palmitic/stearic/ oleic acids) during IVM, oocyte lipid content was not affected even though cumulus cells exhibited lipid accumulation (Aardema et al. 2013). Addition of conjugated linoleic acid (t10,c12CLA) to bovine COCs during maturation increased t10,c12CLA content in both cumulus cells and oocytes, but did not alter total fatty acid levels (Lapa et al. 2011). These studies illustrate that further work is needed to understand in which contexts lipid exposure modifies oocyte lipid content.

Individual fatty acids clearly have distinct effects on oocyte maturation and developmental competence. Treatment of bovine COCs with either stearic acid or palmitic acid (at relatively high doses based on levels in dairy cow follicular fluid) during maturation inhibited cumulus expansion, increased cumulus apoptosis and delayed progression to MII (Leroy et al. 2005a). Treatment of bovine COCs with a mixture of these NEFA (palmitic/ stearic/oleic acid) during IVM upregulated genes involved 
in energy metabolism and oxidative stress (lactate dehydrogenase, glyceraldehyde 3-phosphate dehydrogenase and glutathione peroxidase) in oocytes; interestingly, these same genes were downregulated in cumulus cells (Van Hoeck et al. 2013). Fertilisation of these oocytes gives rise to blastocysts, with significantly lower cell number and increased apoptosis (Van Hoeck et al. 2011). Experiments on mouse indicate that saturated fatty acids, namely palmitic acid, induce ER stress in COCs and mitochondrial dysfunction in oocytes (Wu et al. 2012). Mouse COCs exposed to lipid-rich follicular fluid had similarly increased expression of ER stress genes in association with impaired nuclear maturation (Yang et al. 2012). Importantly, co-treatment with an ER stress inhibitor during maturation reverses impaired cumulus expansion, altered oocyte mitochondrial activity and poor embryo development induced by high doses of palmitic acid (Wu et al. 2012), demonstrating that the detrimental effects of the high lipid environment are mediated through a classic ER stress pathway. Whether fatty acids are saturated or unsaturated also influences oocyte maturation, with unsaturated fatty acids generally having beneficial effects on subsequent embryo development. IVM in the presence of conjugated linoleic acid (t10,c12CLA) improves the morphology of bovine blastocysts (Lapa et al. 2011). Similarly, treatment of bovine COCs with linolenic acid improved maturation to MII and promoted embryo development, effects that seem to be mediated by its ability to influence prostaglandin production (Marei et al. 2009) and increase active MAPK signalling (Marei et al. 2010). Oleic acid reverses the detrimental effects of palmitic acid and stearic acid on cleavage, 8-cell and blastocyst rates (Aardema et al. 2011). It appears, however, that even unsaturated fatty acids are detrimental at high levels because linolenic acid at increasing doses reduces cumulus expansion and impaired maturation (Marei et al. 2009, 2010). Similarly, exposure of maturing bovine oocytes to high dose of oleic acid ( $1 \mathrm{mM}$ in the presence of $10 \%$ serum) delayed progression to $\mathrm{MII}$ and reduced subsequent fertilisation, cleavage and embryo development (Jorritsma et al. 2004).

Importantly, blastocysts generated from oocytes exposed to high lipid in vitro display distinct phenotypes, particularly relating to metabolism. Bovine embryos generated from oocytes that matured in high levels of combination NEFA (palmitic/stearic/oleic acid) have altered transcriptional activity of several genes including higher glucose transporter SLC2A1 (Van Hoeck et al. 2011) and increased expression of two genes involved in fatty acid synthesis, ACSL1 and GPR3 (ACCA) (Van Hoeck et al. 2013). They do not consume more glucose but exhibit altered amino acid turnover and compromised oxidative metabolism; indicators of lower embryo quality and viability (Van Hoeck et al. 2011).

Thus, specific fatty acids have distinct effects on oocyte maturation and it is emerging that in general saturated fatty acids, particularly palmitic acid and stearic acid, which are elevated in follicular fluid in some metabolic contexts are detrimental, while the presence of unsaturated NEFA such as oleic acid and linoleic acid can, at least in some in vitro contexts, counteract these detrimental effects and promote developmental competence.

\section{Triacylglycerol and fatty acid metabolism in the COC Lipolytic metabolism of triacylglycerols}

The utilisation of fatty acids for metabolic fuel necessitates their hydrolysis of triacylglycerol from the glycerol backbone, which is catalysed by lipases. Lipoprotein lipase, an extracellular lipase tethered to capillary walls by heparin sulphate proteoglycans and activated by apolipoprotein ApoC-II on the surface of circulating lipoproteins, hydrolyses lipoprotein triacylglycerolreleasing free fatty acids, which can then be taken up by cells (Fig. 2). Lipolysis of intracellular triacylglycerol within lipid droplets is catalysed by intracellular lipases including LIPE (formerly known as hormone-sensitive lipase (HSL)) and adipocyte triglyceride lipase (ATGL). Intracellular triacylglycerol stored within lipid droplets is surrounded by a phospholipid monolayer and lipid droplet coat proteins of the perilipin family, which regulate droplet size and variously restrict access of intracellular lipases to the neutral core or promote lipolytic activity under the appropriate metabolic or hormonal conditions. The intracellular lipases, Lipe and

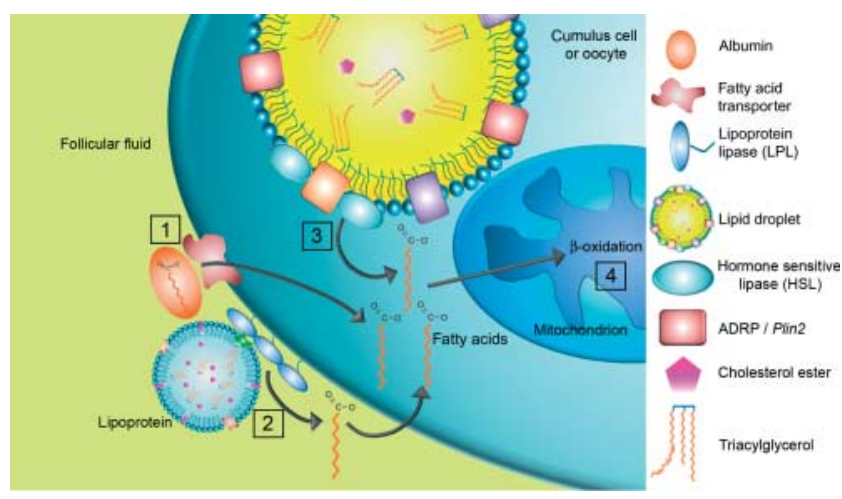

Figure 2 Schematic of proposed mechanisms of mobilisation and catabolism of free fatty acids in the cumulus-oocyte complex. (1) Free fatty acids (FFAs) in follicular fluid are bound to albumin and likely enter cells via fatty acid transporters or directly diffuse the lipid bilayer; however, the exact mechanisms are not known. (2) The mobilisation of triacylglycerol from lipoproteins in follicular fluid may occur via extracellular lipoprotein lipase liberating FFAs, which are then available for cellular uptake. (3) Intracellular triacylglycerol is stored in cumulus cells and oocytes within lipid droplets surrounded by coat proteins including Perilipin2 in oocytes. Upon activation, lipid droplet proteins facilitate lipase-mediated hydrolysis of triacylglycerol and release of FFAs. (4) Intracellular FFAs generated via either transport or lipolysis are then available for metabolism via $\beta$-oxidation in mitochondria. 
Lipc, have been detected in rat ovaries (Hixenbaugh et al. 1989, Lobo et al. 2009), with Lipe localising to the oocyte and cumulus and granulosa cells of large antral follicles (Lobo et al. 2009). Mice lacking the Lipe gene exhibit a significant reduction in ovulation rate and increased numbers of oocytes trapped in corpora lutea (Wade et al. 2002). The ovaries of these mice have no difference in the number of mature antral follicles but decreased numbers of corpora lutea that contribute to reduced $\mathrm{P}_{4}$ levels and decreased fecundity (Wade et al. 2002).

Lipase activity has been measured in bovine oocyte and cumulus cells during IVM and was found to be higher in the oocyte compared with cumulus cells (Cetica et al. 2002). During maturation, lipase activity remained constant in the oocyte while decreased in the cumulus cells (Cetica et al. 2002). Whether these cellspecific patterns of lipolysis hold true in species other than bovine is yet to be determined. Further evidence for triacylglycerol catabolism within the oocyte is the reduction in total intracellular lipid content that is observed during the course of maturation in porcine (Sturmey \& Leese 2003, Alvarez et al. 2012) and bovine oocytes (Ferguson \& Leese 1999, Kim et al. 2001).

Thus, lipase enzymes and activity are detected in COCs and likely to be regulated during the course of maturation. Based on their roles in other cells, it is proposed that extracellular lipases may mediate the transfer of fatty acids from follicular fluid lipoproteins into cumulus cells and that intracellular lipases via interactions with lipid droplet proteins, such as Perilipin-2, which is expressed in oocytes (Yang et al. 2010, Aardema et al. 2011), release fatty acids from stores in the oocyte (Fig. 2). Mechanistic studies are needed, however, to clarify this as well as to demonstrate whether modulation of triacylglycerol metabolism in the COC would have a significant impact on oocyte developmental competence and embryo development.

\section{Metabolism of fatty acids for the production of ATP}

Fatty acids for energy production are transported into the cells from circulation via fatty acid transporter proteins or direct diffusion through the lipid bilayer; thus, NEFA in follicular fluid may also enter cumulus cells and oocytes via similar mechanisms (Fig. 2). However, whether cumulus cells and oocytes preferentially uptake fatty acids from the extracellular milieu or generate fatty acids intracellularly from lipid droplet stores is not known and almost certainly would be differentially regulated in different hormonal and nutritional contexts. Subsequent to either mechanism, however, the catabolism of fatty acids to yield ATP occurs in the mitochondrial matrix via $\beta$-oxidation. The oxidation of fatty acids within ovulated mouse oocytes was first implied in a study by Hillman \& Flynn (1980), in which incorporation of ${ }^{14} \mathrm{C}$-palmitic acid into oocytes was reported. This was confirmed by a study demonstrating that $\beta$-oxidation, measured as metabolism of ${ }^{3} \mathrm{H}$-palmitic acid, dramatically increases during COC maturation in vitro with a significant proportion of this metabolism occurring in the oocyte, although the majority is within the cumulus cells (Dunning et al. 2010).

Only a few studies to date have investigated the expression profile of genes involved in the regulation of $\beta$-oxidation and how these change during oocyte development and nuclear maturation. Cpt $1 b$, whose gene product is responsible for the entry of long-chain fatty acids into the mitochondria, is significantly induced in mouse COCs in the peri-ovulatory maturation phase in vivo (Dunning et al. 2010). The expression of Cpt1b within the mouse oocyte itself at the MIl stage has also been reported (Gentile et al. 2004). Recently, gene transcripts involved in $\beta$-oxidation, including acyl-CoA synthetases, acyl-CoA dehydrogenases and enoyl-CoA hydratase, have been detected in human oocytes and cumulus cells (Montjean et al. 2012). Activity of these enzymes involved in the $\beta$-oxidation spiral have also been detected in human oocytes and, interestingly, found to be negatively associated with maternal age (Yazigi et al. 1993).

\section{Necessity for lipid metabolism in oocyte developmental potential}

$\beta$-oxidation is likely to be important in the acquisition of oocyte developmental competence and female fertility. Ablation of $A \operatorname{cox} 1$, a gene involved in $\beta$-oxidation of very long-chain fatty acids, leads to sterility in female mice associated with smaller ovaries (Fan et al. 1996); however, the physiological mechanism linking Acox 1 function and female sterility is yet to be investigated. There is also an interesting case study of a female patient with a functional mutation in the CPTII gene, seeking fertility treatment (Hull et al. 2009). The oocytes and embryos of this patient were predicted to have CPTII enzyme deficiency until activation of the embryonic genome at the 8-cell stage and as such the culture media were adjusted to include more glucose for the culture of intact COCs and increased levels of pyruvate for cleavage stage embryos (Hull et al. 2009). While two previous intrauterine insemination cycles had failed, ICSI using carbohydrate-supplemented media resulted in the birth of a singleton baby, suggesting that plasticity in embryo metabolism allows for increased glycolysis to support development when $\beta$-oxidation is compromised.

$\beta$-oxidation is reduced in both oocytes and cumulus cells that mature in vitro compared with COCs matured in vivo, demonstrating that this metabolic pathway is acutely regulated by follicular factors at the time of ovulation. $\beta$-oxidation (oxidation of ${ }^{14} \mathrm{C}$-palmitic acid) in cat oocytes maturing in vitro was significantly less than oocytes that had matured in vivo (Spindler et al. 2000). In rhesus monkey, microarray analysis found that several lipid metabolism genes, including some involved in $\beta$-oxidation, were dysregulated in cumulus cells 
following IVM compared with those matured in vivo (Lee et al. 2011). In porcine oocytes, levels of ACSL3 and $A C A D L$, which activate long-chain fatty acids before their entry into mitochondria and catalyse the first step in the $\beta$-oxidation spiral respectively, were found to be dysregulated in another model of poor oocyte developmental competence (Yuan et al. 2011). Recently we have found that mouse COCs matured in vitro metabolise fatty acid at less than half the rate of COCs matured in vivo, in association with dysregulated expression of at least 15 genes involved in fatty acid activation, transport and oxidation (Dunning et al. 2014).

Studies using pharmacological inhibitors have confirmed the essential role of $\beta$-oxidation in both oocyte nuclear maturation and the acquisition of developmental competence. $\beta$-oxidation is required for the resumption of meiosis and nuclear maturation in the mouse (Downs et al. 2009, Paczkowski et al. 2013, Valsangkar \& Downs 2013), bovine and porcine oocyte (Paczkowski et al. 2013). Furthermore, inhibition of $\beta$-oxidation during oocyte maturation in numerous species demonstrates that this form of metabolism is important for subsequent embryo development. Immature bovine oocytes exposed to methyl palmoxirate, which inhibits CPT1, exhibit reduced oxygen consumption and impaired capacity to develop to the blastocyst stage (Ferguson \& Leese 2006). Similarly, treatment of porcine oocytes during maturation with methyl palmoxirate or mercaptoacetate, an inhibitor of 3-hydroxyl CoA dehydrogenase in the $\beta$-oxidation spiral, resulted in impaired fertilisation and decreased blastocyst development (Sturmey et al. 2006). We have shown similar sensitivities of mouse oocytes to the inhibition of $\beta$-oxidation, in which treatment of COCs with etomoxir, an inhibitor of Cpt1, results in a significant decrease in $\beta$-oxidation and significantly fewer blastocyst embryos following fertilisation (Dunning et al. 2010).

The requirement for $\beta$-oxidation during oocyte maturation for subsequent embryo development in the mouse is interesting in light of their comparatively low levels of intracellular lipid stores compared with bovine and porcine oocytes (reviewed in Sturmey et al. (2009) and see Fig. 1). However, triacylglycerol stores are energy dense and metabolism of a relatively small amount of lipid produces large amounts of ATP; thus despite the low levels of stored lipid in the mouse oocyte, it appears to be essential for oocyte maturation and quality.

\section{Promoting $\beta$-oxidation to improve oocyte developmental outcomes}

Upregulation of $\beta$-oxidation in COCs in vitro has also been used to demonstrate the importance of this metabolic pathway for developmental competence. Carnitine is an essential co-factor required for the entry of long-chain fatty acids into the mitochondrion. Supplementation of culture medium with L-carnitine significantly increases $\beta$-oxidation in mouse COCs maturing in vitro and in follicles grown in vitro (Dunning et al. 2010, 2011). This increased level of $\beta$-oxidation was associated with a significant improvement in oocyte quality as demonstrated by the ability of fertilised oocytes to reach the blastocyst stage of development (Dunning et al. 2010, 2011) and a higher number of cells allocated to the inner cell mass (Dunning et al. 2010). Others have also demonstrated a clear benefit of L-carnitine on oocyte maturation and developmental competence during IVM of porcine oocytes (Hashimoto 2009, Somfai et al. 2011, Wu et al. 2011, You et al. 2012) which are heavily laden with intracellular lipid. L-carnitine supplementation is associated with redistribution of intracellular lipid droplet in bovine oocytes (Chankitisakul et al. 2013), a reduction in intracellular lipid content in porcine oocytes (Somfai et al. 2011) and a significant increase in oocyte mitochondrial activity in mouse (Wu et al. 2012), bovine (Hashimoto 2009) and porcine (Somfai et al. 2011) oocytes. In addition, we have shown that L-carnitine, in the absence of other energy substrates, significantly improves embryo development in both mouse (Dunning et al. 2010) and bovine (Sutton-McDowall et al. 2012) pre-implantation embryos, indicating that L-carnitine stimulates metabolism of intracellular lipid stores. In other studies, L-carnitine supplementation was associated with decreased oocyte cytoskeletal damage (Mansour et al. 2009) and reversed the negative effects of repeated superovulation, i.e. the decreased number and abnormal distribution of mitochondria and impaired development to blastocyst (Miyamoto et al. 2010).

While -carnitine has known anti-oxidant properties, its ability to upregulate $\beta$-oxidation and improve oocyte quality suggests that the beneficial effects of L-carnitine during oocyte maturation are attributable, at least in part, to its role in promoting lipid metabolism. Furthermore, human oocytes and cumulus cells lack transcripts for the genes involved in the biosynthetic pathway for carnitine production (Montjean et al. 2012). In vivo carnitine is most likely to be sourced from the follicular fluid from which levels are abundant and reflect those that found in serum (Dunning \& Robker 2012, Montjean et al. 2012, Valckx et al. 2012); however, in vitro cultures of COCs would lack carnitine and are likely to be deficient in $\beta$-oxidation. Thus the potential to improve human oocyte quality during IVM by modulating $\beta$-oxidation, including with L-carnitine warrants further investigation.

\section{Summary}

Lipid metabolism is induced in COCs during maturation and beneficial to oocyte developmental potential; however, to date the characterisation of lipases and key $\beta$-oxidation enzymes involved has been limited. Inhibitor studies have demonstrated that lipolysis and $\beta$-oxidation within the maturing COC significantly influence 
subsequent embryo development. Yet it is not clear which are the essential regulatory gene products associated with oocyte developmental competence and optimal preimplantation embryo development. Thus, further studies are required to elucidate the complete expression profile of metabolic regulatory genes during folliculogenesis, particularly during the final stages of COC maturation which will also help to identify the lipid types most important to the peri-conception oocyte.

Lipoproteins derived from blood are prevalent in follicular fluid and may contribute to oocyte development. Whether lipoproteins transport triacylglycerides to ovarian cells for energy production similar to their roles in other cells is less clear, but there is mounting evidence for this as an important metabolic pathway in maturing ovarian follicles. Within cells, triacylglycerides are stored in lipid droplets and these are prevalent and being characterised molecularly in the oocytes and cumulus cells of many species. Much remains to be determined about how the metabolism of triacylglycerides by lipolysis and fatty acids by $\beta$-oxidation is regulated in cumulus cells and oocytes and the relative importance of this form of energy production for female fertility.

Specific fatty acids, particularly saturated vs unsaturated, have clearly distinct effects on oocyte maturation and developmental competence. Thus, oocyte and embryo development in vitro may be optimised through the provision of appropriate energy substrates and essential co-factors. Similarly, the influence of physiological conditions, such as diet, on the supply of fatty acids to the COC in vivo warrants further investigation. Through greater understanding of the in vivo regulation of lipid levels, lipid metabolism and essential co-factors, strategies may be developed to improve oocyte developmental potential in domestic animals and alleviate sub-fertility in women.

\section{Declaration of interest}

The authors declare that there is no conflict of interest that could be perceived as prejudicing the impartiality of the review.

\section{Funding}

The authors are supported by grants from the Australian Research Council (ARC), the National Health and Medical Research Council, The Women's and Children's Hospital Foundation and The Channel 7 Children's Research Foundation.

\section{Acknowledgements}

The authors gratefully acknowledge Dr Tawiwan Pantasri, Michael Barry and Paula Scanlon (Fertility SA, Adelaide, South Australia) for facilitating and performing the analysis of human oocyte lipid content; and Dr Melanie Sutton-McDowell,
Stephen Mcllfatrick, Lesley Ritter and Ryan Rose for providing abattoir-derived oocytes for staining.

\section{References}

Aardema H, Vos PL, Lolicato F, Roelen BA, Knijn HM, Vaandrager AB, Helms JB \& Gadella BM 2011 Oleic acid prevents detrimental effects of saturated fatty acids on bovine oocyte developmental competence. Biology of Reproduction 85 62-69. (doi:10.1095/biolreprod.110.088815)

Aardema $\mathrm{H}$, Lolicato $\mathrm{F}$, van de Lest $\mathrm{CH}$, Brouwers JF, Vaandrager $\mathrm{AB}$, van Tol HT, Roelen BA, Vos PL, Helms JB \& Gadella BM 2013 Bovine cumulus cells protect maturing oocytes from increased fatty acid levels by massive intracellular lipid storage. Biology of Reproduction 88164. (doi:10.1095/biolreprod.112.106062)

Adamiak SJ, Powell K, Rooke JA, Webb R \& Sinclair KD 2006 Body composition, dietary carbohydrates and fatty acids determine post-fertilisation development of bovine oocytes in vitro. Reproduction 131 247-258. (doi:10.1530/rep.1.00871)

Alvarez GM, Dalvit GC \& Cetica PD 2012 Influence of the cumulus and gonadotropins on the metabolic profile of porcine cumulus-oocyte complexes during in vitro maturation. Reproduction in Domestic Animals 47 856-864. (doi:10.1111/j.1439-0531.2011.01943.x)

Ami D, Mereghetti P, Natalello A, Doglia SM, Zanoni M, Redi CA \& Monti M 2011 FTIR spectral signatures of mouse antral oocytes: molecular markers of oocyte maturation and developmental competence. Biochimica et Biophysica Acta 1813 1220-1229. (doi:10.1016/ j.bbamcr.2011.03.009)

Auclair S, Uzbekov R, Elis S, Sanchez L, Kireev I, Lardic L, Dalbies-Tran R \& Uzbekova S 2013 Absence of cumulus cells during in vitro maturation affects lipid metabolism in bovine oocytes. American Journal of Physiology. Endocrinology and Metabolism 304 E599-E613. (doi:10.1152/ajpendo.00469.2012)

Awasthi H, Saravia F, Rodriguez-Martinez H \& Bage R 2010 Do cytoplasmic lipid droplets accumulate in immature oocytes from over-conditioned repeat breeder dairy heifers? Reproduction in Domestic Animals 45 e194-e198.

Azhar S, Tsai L, Medicherla S, Chandrasekher Y, Giudice L \& Reaven E 1998 Human granulosa cells use high density lipoprotein cholesterol for steroidogenesis. Journal of Clinical Endocrinology and Metabolism 83 983-991.

Bender K, Walsh S, Evans AC, Fair T \& Brennan L 2010 Metabolite concentrations in follicular fluid may explain differences in fertility between heifers and lactating cows. Reproduction 139 1047-1055. (doi:10.1530/REP-10-0068)

Biggers JD, Whittingham DG \& Donahue RP 1967 The pattern of energy metabolism in the mouse oocyte and zygote. PNAS 58 560-567. (doi:10.1073/pnas.58.2.560)

Browne RW, Shelly WB, Bloom MS, Ocque AJ, Sandler JR, Huddleston HG \& Fujimoto VY 2008 Distributions of high-density lipoprotein particle components in human follicular fluid and sera and their associations with embryo morphology parameters during IVF. Human Reproduction 23 1884-1894. (doi:10.1093/humrep/den183)

Browne RW, Bloom MS, Shelly WB, Ocque AJ, Huddleston HG \& Fujimoto VY 2009 Follicular fluid high density lipoprotein-associated micronutrient levels are associated with embryo fragmentation during IVF. Journal of Assisted Reproduction and Genetics 26 557-560. (doi:10.1007/s10815-009-9367-x)

Buckett WM, Chian RC, Dean NL, Sylvestre C, Holzer HE \& Tan SL 2008 Pregnancy loss in pregnancies conceived after in vitro oocyte maturation, conventional in vitro fertilization, and intracytoplasmic sperm injection. Fertility and Sterility 90 546-550. (doi:10.1016/j.fertnstert.2007.06.107)

Cetica P, Pintos L, Dalvit G \& Beconi M 2002 Activity of key enzymes involved in glucose and triglyceride catabolism during bovine oocyte maturation in vitro. Reproduction 124 675-681. (doi:10.1530/rep.0. 1240675)

Chankitisakul V, Somfai T, Inaba Y, Techakumphu M \& Nagai T 2013 Supplementation of maturation medium with L-carnitine improves cryo-tolerance of bovine in vitro matured oocytes. Theriogenology 79 590-598. (doi:10.1016/j.theriogenology.2012.11.011) 
Childs S, Hennessy AA, Sreenan JM, Wathes DC, Cheng Z, Stanton C, Diskin MG \& Kenny DA 2008 Effect of level of dietary n-3 polyunsaturated fatty acid supplementation on systemic and tissue fatty acid concentrations and on selected reproductive variables in cattle. Theriogenology 70 595-611. (doi:10.1016/j.theriogenology. 2008.04.002)

Downs SM 1995 The influence of glucose, cumulus cells, and metabolic coupling on ATP levels and meiotic control in the isolated mouse oocyte. Developmental Biology 167 502-512. (doi:10.1006/dbio.1995.1044)

Downs SM, Mosey JL \& Klinger J 2009 Fatty acid oxidation and meiotic resumption in mouse oocytes. Molecular Reproduction and Development 76 844-853. (doi:10.1002/mrd.21047)

Dunning KR \& Robker RL 2012 Promoting lipid utilization with L-carnitine to improve oocyte quality. Animal Reproduction Science 134 69-75. (doi:10.1016/j.anireprosci.2012.08.013)

Dunning KR, Cashman K, Russell DL, Thompson JG, Norman RJ \& Robker RL 2010 B-oxidation is essential for mouse oocyte developmental competence and early embryo development. Biology of Reproduction $\mathbf{8 3}$ 909-918. (doi:10.1095/biolreprod.110.084145)

Dunning KR, Akison LK, Russell DL, Norman RJ \& Robker RL 2011 Increased $\beta$-oxidation and improved oocyte developmental competence in response to L-carnitine during ovarian in vitro follicle development in mice. Biology of Reproduction 85 548-555. (doi:10.1095/biolreprod.110.090415)

Dunning KR, Anastasi MR, Zhang VJ, Russell DL \& Robker RL 2014 Regulation of fatty acid oxidation in mouse cumulus-oocyte complexes during maturation and modulation by PPAR agonists. PLOS ONE 9 e87327. (doi:10.1371/journal.pone.0087327)

Fan CY, Pan J, Chu R, Lee D, Kluckman KD, Usuda N, Singh I, Yeldandi AV, Rao MS, Maeda N et al. 1996 Hepatocellular and hepatic peroxisomal alterations in mice with a disrupted peroxisomal fatty acyl-coenzyme A oxidase gene. Journal of Biological Chemistry 271 24698-24710. (doi:10.1074/jbc.271.44.27237)

Ferguson EM \& Leese HJ 1999 Triglyceride content of bovine oocytes and early embryos. Journal of Reproduction and Fertility 116 373-378.

Ferguson EM \& Leese HJ 2006 A potential role for triglyceride as an energy source during bovine oocyte maturation and early embryo development. Molecular Reproduction and Development 73 1195-1201. (doi:10. 1002/mrd.20494)

Ferreira CR, Saraiva SA, Catharino RR, Garcia JS, Gozzo FC, Sanvido GB, Santos LF, Lo Turco EG, Pontes JH, Basso AC et al. 2010 Single embryo and oocyte lipid fingerprinting by mass spectrometry. Journal of Lipid Research 51 1218-1227. (doi:10.1194/jlr.D001768)

Gautier T, Becker S, Drouineaud V, Menetrier F, Sagot P, Nofer JR, von Otte S, Lagrost L, Masson D \& Tietge UJ 2010 Human luteinized granulosa cells secrete apoB100-containing lipoproteins. Journal of Lipid Research 51 2245-2252. (doi:10.1194/jlr.M005181)

Genicot G, Leroy JL, Soom AV \& Donnay I 2005 The use of a fluorescent dye, Nile red, to evaluate the lipid content of single mammalian oocytes. Theriogenology 63 1181-1194. (doi:10.1016/j.theriogenology. 2004.06.006)

Gentile L, Monti M, Sebastiano V, Merico V, Nicolai R, Calvani M, Garagna S, Redi CA \& Zuccotti M 2004 Single-cell quantitative RT-PCR analysis of Cpt $1 \mathrm{~b}$ and $\mathrm{Cpt} 2$ gene expression in mouse antral oocytes and in preimplantation embryos. Cytogenetic and Genome Research 105 215-221. (doi:10.1159/000078191)

Gilchrist RB \& Thompson JG 2007 Oocyte maturation: emerging concepts and technologies to improve developmental potential in vitro. Theriogenology 67 6-15. (doi:10.1016/j.theriogenology.2006.09.027)

Hashimoto S 2009 Application of in vitro maturation to assisted reproductive technology. Journal of Reproduction and Development 55 $1-10$.

Hillman N \& Flynn TJ 1980 The metabolism of exogenous fatty acids by preimplantation mouse embryos developing in vitro. Journal of Embryology and Experimental Morphology 56 157-168.

Hixenbaugh EA, Sullivan TR Jr, Strauss JF III, Laposata EA, Komaromy M \& Paavola LG 1989 Hepatic lipase in the rat ovary. Ovaries cannot synthesize hepatic lipase but accumulate it from the circulation. Journal of Biological Chemistry 264 4222-4230.

Homa ST \& Brown CA 1992 Changes in linoleic acid during follicular development and inhibition of spontaneous breakdown of germinal vesicles in cumulus-free bovine oocytes. Journal of Reproduction and Fertility 94 153-160. (doi:10.1530/jrf.0.0940153)
Homa ST, Racowsky C \& McGaughey RW 1986 Lipid analysis of immature pig oocytes. Journal of Reproduction and Fertility 77 425-434. (doi:10. 1530/jrf.0.0770425)

Hughes J, Kwong WY, Li D, Salter AM, Lea RG \& Sinclair KD 2011 Effects of omega- 3 and -6 polyunsaturated fatty acids on ovine follicular cell steroidogenesis, embryo development and molecular markers of fatty acid metabolism. Reproduction 141 105-118. (doi:10.1530/REP-100337REF37=10.1016/j.fertnstert.2009.01.104)

Hull ML, Nemeth D, Hague WM, Wilkinson C, Liebelt J, Lane M \& Feil D 2009 Mitochondrial fatty acid transport enzyme deficiency implications for in vitro fertilization. Fertility and Sterility 91 2732.e2711-2732.e2734. (doi:10.1016/j.fertnstert.2009.01.104)

Igosheva N, Abramov AY, Poston L, Eckert JJ, Fleming TP, Duchen MR \& McConnell J 2010 Maternal diet-induced obesity alters mitochondrial activity and redox status in mouse oocytes and zygotes. PLOS ONE 5 e10074. (doi:10.1371/journal.pone.0010074)

Jaspard B, Fournier N, Vieitez G, Atger V, Barbaras R, Vieu C, Manent J, Chap H, Perret B \& Collet X 1997 Structural and functional comparison of HDL from homologous human plasma and follicular fluid. A model for extravascular fluid. Arteriosclerosis, Thrombosis, and Vascular Biology 17 1605-1613. (doi:10.1161/01.ATV.17.8.1605)

Jeong WJ, Cho SJ, Lee HS, Deb GK, Lee YS, Kwon TH \& Kong IK 2009 Effect of cytoplasmic lipid content on in vitro developmental efficiency of bovine IVP embryos. Theriogenology 72 584-589. (doi:10.1016/j. theriogenology.2009.04.015)

Jorritsma R, de Groot MW, Vos PL, Kruip TA, Wensing T \& Noordhuizen JP 2003 Acute fasting in heifers as a model for assessing the relationship between plasma and follicular fluid NEFA concentrations. Theriogenology 60 151-161. (doi:10.1016/S0093-691X(02)01358-4)

Jorritsma R, Cesar ML, Hermans JT, Kruitwagen CL, Vos PL \& Kruip TA 2004 Effects of non-esterified fatty acids on bovine granulosa cells and developmental potential of oocytes in vitro. Animal Reproduction Science 81 225-235. (doi:10.1016/j.anireprosci.2003.10.005)

Jungheim ES, Macones GA, Odem RR, Patterson BW, Lanzendorf SE, Ratts VS \& Moley KH 2011 Associations between free fatty acids, cumulus-oocyte complex morphology and ovarian function during in vitro fertilization. Fertility and Sterility 95 1970-1974. (doi:10.1016/j. fertnstert.2011.01.154)

Kikuchi K, Ekwall H, Tienthai P, Kawai Y, Noguchi J, Kaneko H \& Rodriguez-Martinez H 2002 Morphological features of lipid droplet transition during porcine oocyte fertilisation and early embryonic development to blastocyst in vivo and in vitro. Zygote 10 355-366. (doi:10.1017/S0967199402004100)

Kim JY, Kinoshita M, Ohnishi M \& Fukui Y 2001 Lipid and fatty acid analysis of fresh and frozen-thawed immature and in vitro matured bovine oocytes. Reproduction 122 131-138. (doi:10.1530/rep.0.1220131)

Kruip TAM, Cran DG, van Beneden TH \& Dieleman SJ 1983 Structural changes in bovine oocytes during final maturation in vivo. Gamete Research 8 29-47. (doi:10.1002/mrd.1120080105)

Lapa M, Marques CC, Alves SP, Vasques MI, Baptista MC, Carvalhais I, Silva Pereira M, Horta AE, Bessa RJ \& Pereira RM 2011 Effect of trans-10 cis-12 conjugated linoleic acid on bovine oocyte competence and fatty acid composition. Reproduction in Domestic Animals 46 904-910. (doi:10.1111/j.1439-0531.201REF46=10.1002/mrd.1120080105)

Lee YS, VandeVoort CA, Gaughan JP, Midic U, Obradovic Z \& Latham KE 2011 Extensive effects of in vitro oocyte maturation on rhesus monkey cumulus cell transcriptome. American Journal of Physiology. Endocrinology and Metabolism 301 E196-E209. (doi:10.1152/ajpendo.00686.2010)

Leroy JL, Vanholder T, Delanghe JR, Opsomer G, Van Soom A, Bols PE \& de Kruif A 2004a Metabolite and ionic composition of follicular fluid from different-sized follicles and their relationship to serum concentrations in dairy cows. Animal Reproduction Science 80 201-211. (doi:10.1016/ S0378-4320(03)00173-8)

Leroy JL, Vanholder T, Delanghe JR, Opsomer G, Van Soom A, Bols PE, Dewulf J \& de Kruif A 2004b Metabolic changes in follicular fluid of the dominant follicle in high-yielding dairy cows early post partum. Theriogenology 62 1131-1143. (doi:10.1016/j.theriogenology.2003. 12.017)

Leroy JL, Vanholder T, Mateusen B, Christophe A, Opsomer G, de Kruif A, Genicot G \& Van Soom A 2005a Non-esterified fatty acids in follicular fluid of dairy cows and their effect on developmental capacity of bovine oocytes in vitro. Reproduction 130 485-495. (doi:10.1530/rep.1.00735) 
Leroy JL, Genicot G, Donnay I \& Van Soom A 2005b Evaluation of the lipid content in bovine oocytes and embryos with nile red: a practical approach. Reproduction in Domestic Animals 40 76-78. (doi:10.1111/j. 1439-0531.2004.00556.x)

Leroy JL, Opsomer G, Van Soom A, Goovaerts IG \& Bols PE 2008a Reduced fertility in high-yielding dairy cows: are the oocyte and embryo in danger? Part I. The importance of negative energy balance and altered corpus luteum function to the reduction of oocyte and embryo quality in high-yielding dairy cows Reproduction in Domestic Animals 43 612-622. (doi:10.1111/j.1439-0531.2007.00960.x)

Leroy JL, Van Soom A, Opsomer G, Goovaerts IG \& Bols PE $2008 b$ Reduced fertility in high-yielding dairy cows: are the oocyte and embryo in danger? Part II. Mechanisms linking nutrition and reduced oocyte and embryo quality in high-yielding dairy cows Reproduction in Domestic Animals 43 623-632. (doi:10.1111/j.1439-0531.2007.00961.x)

Leroy JL, Rizos D, Sturmey R, Bossaert P, Gutierrez-Adan A, Van Hoeck V, Valckx S \& Bols PE 2011 Intrafollicular conditions as a major link between maternal metabolism and oocyte quality: a focus on dairy cow fertility. Reproduction, Fertility, and Development 24 1-12. (doi:10. 1071/RD11901)

Lobo MV, Huerta L, Arenas MI, Busto R, Lasuncion MA \& Martin-Hidalgo A 2009 Hormone-sensitive lipase expression and IHC localization in the rat ovary, oviduct, and uterus. Journal of Histochemistry and Cytochemistry 57 51-60. (doi:10.1369/jhc.2008.951996)

Loewenstein JE \& Cohen Al 1964 Dry mass, lipid content and protein content of the intact and zona-free mouse ovum. Journal of Embryology and Experimental Morphology 12 113-121.

Mansour G, Abdelrazik H, Sharma RK, Radwan E, Falcone T \& Agarwal A 2009 L-carnitine supplementation reduces oocyte cytoskeleton damage and embryo apoptosis induced by incubation in peritoneal fluid from patients with endometriosis. Fertility and Sterility 91 2079-2086. (doi:10. 1016/j.fertnstert.2008.02.097)

Marei WF, Wathes DC \& Fouladi-Nashta AA 2009 The effect of linolenic acid on bovine oocyte maturation and development. Biology of Reproduction 81 1064-1072. (doi:10.1095/biolreprod.109.076851)

Marei WF, Wathes DC \& Fouladi-Nashta AA 2010 Impact of linoleic acid on bovine oocyte maturation and embryo development. Reproduction 139 979-988. (doi:10.1530/REP-09-0503)

Martins LR, Fernandes CB, Minto BW, Landim-Alvarenga FC \& Lopes MD 2009 Ultrastructural characteristics of non-matured and in vitro matured oocytes collected from pre-pubertal and adult domestic cat ovaries. Reproduction in Domestic Animals 44 251-254. (doi:10.1111/j.14390531.2009.01389.x)

Matorras R, Ruiz J, Mendoza R, Ruiz N, Sanjurjo P \& RodriguezEscudero FJ 1998 Fatty acid composition of fertilization-failed human oocytes. Human Reproduction 13 2227-2230. (doi:10.1093/humrep/13. 8.2227)

McEvoy TG, Coull GD, Broadbent PJ, Hutchinson JS \& Speake BK 2000 Fatty acid composition of lipids in immature cattle, pig and sheep oocytes with intact zona pellucida. Journal of Reproduction and Fertility 118 163-170.

McKeegan PJ \& Sturmey RG 2011 The role of fatty acids in oocyte and early embryo development. Reproduction, Fertility, and Development 24 59-67. (doi:10.1071/RD11907)

Miettinen HE, Rayburn H \& Krieger M 2001 Abnormal lipoprotein metabolism and reversible female infertility in $\mathrm{HDL}$ receptor (SR-BI)deficient mice. Journal of Clinical Investigation 108 1717-1722. (doi:10. 1172/JCl13288)

Miyamoto K, Sato EF, Kasahara E, Jikumaru M, Hiramoto K, Tabata $\mathbf{H}$, Katsuragi M, Odo S, Utsumi K \& Inoue M 2010 Effect of oxidative stress during repeated ovulation on the structure and functions of the ovary, oocytes, and their mitochondria. Free Radical Biology \& Medicine 49 674-681. (doi:10.1016/j.freeradbiomed.2010.05.025)

Monti M, Zanoni M, Calligaro A, Ko MS, Mauri P \& Redi CA 2013 Developmental arrest and mouse antral not-surrounded nucleolus oocytes. Biology of Reproduction 88 2. (doi:10.1095/biolreprod.112. 103887)

Montjean D, Entezami F, Lichtblau I, Belloc S, Gurgan T \& Menezo Y 2012 Carnitine content in the follicular fluid and expression of the enzymes involved in $\beta$ oxidation in oocytes and cumulus cells. Journal of Assisted Reproduction and Genetics 29 1221-1225. (doi:10.1007/s10815-0129855-2)
Paczkowski M, Silva E, Schoolcraft WB \& Krisher RL 2013 Comparative importance of fatty acid $\beta$-oxidation to nuclear maturation, gene expression, and glucose metabolism in mouse, bovine, and porcine cumulus-oocyte complexes. Biology of Reproduction 88 111. (doi:10. 1095/biolreprod.113.108548)

Perret BP, Parinaud J, Ribbes H, Moatti JP, Pontonnier G, Chap H \& DousteBlazy L 1985 Lipoprotein and phospholipid distribution in human follicular fluids. Fertility and Sterility 43 405-409.

Preis KA, Seidel GE Jr \& Gardner DK 2007 Reduced oxygen concentration improves the developmental competence of mouse oocytes following in vitro maturation. Molecular Reproduction and Development $\mathbf{7 4}$ 893-903. (doi:10.1002/mrd.20655)

Renaville B, Bacciu N, Comin A, Motta M, Poli I, Vanini G \& Prandi A 2010 Plasma and follicular fluid fatty acid profiles in dairy cows. Reproduction in Domestic Animals 45 118-121. (doi:10.1111/j.1439-0531.2008.01264.x)

Rizos D, Ward F, Duffy P, Boland MP \& Lonergan P 2002 Consequences of bovine oocyte maturation, fertilization or early embryo development in vitro versus in vivo: implications for blastocyst yield and blastocyst quality. Molecular Reproduction and Development 61 234-248. (doi:10. 1002/mrd.1153)

Robker RL, Akison LK, Bennett BD, Thrupp PN, Chura LR, Russell DL, Lane M \& Norman RJ 2009 Obese women exhibit differences in ovarian metabolites, hormones, and gene expression compared with moderateweight women. Journal of Clinical Endocrinology and Metabolism 94 1533-1540. (doi:10.1210/jc.2008-2648)

Romek M, Gajda B, Krzysztofowicz E, Kepczynski M \& Smorag Z 2011 New technique to quantify the lipid composition of lipid droplets in porcine oocytes and pre-implantation embryos using Nile Red fluorescent probe. Theriogenology 75 42-54. (doi:10.1016/j.theriogenology.2010.06.040)

Shalgi R, Kraicer P, Rimon A, Pinto M \& Soferman N 1973 Proteins of human follicular fluid: the blood-follicle barrier. Fertility and Sterility $\mathbf{2 4}$ 429-434.

Simpson ER, Rochelle DB, Carr BR \& MacDonald PC 1980 Plasma lipoproteins in follicular fluid of human ovaries. Journal of Clinical Endocrinology and Metabolism 51 1469-1471. (doi:10.1210/jcem-51-6-1469)

Somfai T, Kaneda M, Akagi S, Watanabe S, Haraguchi S, Mizutani E, DangNguyen TQ, Geshi M, Kikuchi K \& Nagai T 2011 Enhancement of lipid metabolism with L-carnitine during in vitro maturation improves nuclear maturation and cleavage ability of follicular porcine oocytes. Reproduction, Fertility, and Development 23 912-920. (doi:10.1071/RD10339)

Spindler RE, Pukazhenthi BS \& Wildt DE 2000 Oocyte metabolism predicts the development of cat embryos to blastocyst in vitro. Molecular Reproduction and Development 56 163-171. (doi:10.1002/(SICI)10982795(200006)56:2 < 163::AID-MRD7>3.0.CO;2-3)

Sturmey RG \& Leese HJ 2003 Energy metabolism in pig oocytes and early embryos. Reproduction 126 197-204. (doi:10.1530/rep.0.1260197)

Sturmey RG, O'Toole PJ \& Leese HJ 2006 Fluorescence resonance energy transfer analysis of mitochondrial:lipid association in the porcine oocyte. Reproduction 132 829-837. (doi:10.1530/REP-06-0073)

Sturmey RG, Reis A, Leese HJ \& McEvoy TG 2009 Role of fatty acids in energy provision during oocyte maturation and early embryo development. Reproduction in Domestic Animals 44 (Suppl 3) 50-58. (doi:10. 1111/j.1439-0531.2009.01402.x)

Su YQ, Sugiura K, Wigglesworth K, O'Brien MJ, Affourtit JP, Pangas SA, Matzuk MM \& Eppig JJ 2008 Oocyte regulation of metabolic cooperativity between mouse cumulus cells and oocytes: BMP15 and GDF9 control cholesterol biosynthesis in cumulus cells. Development 135 111-121. (doi:10.1242/dev.009068)

Sugiura K \& Eppig JJ 2005 Society for Reproductive Biology Founders' Lecture 2005. Control of metabolic cooperativity between oocytes and their companion granulosa cells by mouse oocytes. Reproduction, Fertility, and Development 17 667-674. (doi:10.1071/RD05071)

Sutton-McDowall ML, Feil D, Robker RL, Thompson JG \& Dunning KR 2012 Utilization of endogenous fatty acid stores for energy production in bovine preimplantation embryos. Theriogenology 77 1632-1641. (doi:10.1016/j.theriogenology.2011.12.008)

Thompson JG, Lane M \& Gilchrist RB 2007 Metabolism of the bovine cumulus-oocyte complex and influence on subsequent developmental competence. Society of Reproduction and Fertility Supplement 64 179-190. 
Tsujii H, Khandoker MAMY \& Hamano K 2001 Lipid in mammalian embryo development. Journal of Mammalian Ova Research 18 73-80. (doi:10.1274/jmor.18.73)

Valckx SD, De Pauw I, De Neubourg D, Inion I, Berth M, Fransen E, Bols PE \& Leroy JL 2012 BMI-related metabolic composition of the follicular fluid of women undergoing assisted reproductive treatment and the consequences for oocyte and embryo quality. Human Reproduction 27 3531-3539. (doi:10.1093/humrep/des350)

Valkenburg O, Steegers-Theunissen RP, Smedts HP, Dallinga-Thie GM, Fauser BC, Westerveld EH \& Laven JS 2008 A more atherogenic serum lipoprotein profile is present in women with polycystic ovary syndrome: a case-control study. Journal of Clinical Endocrinology and Metabolism 93 470-476. (doi:10.1210/jc.2007-1756)

Valsangkar D \& Downs SM 2013 A requirement for fatty acid oxidation in the hormone-induced meiotic maturation of mouse oocytes. Biology of Reproduction 89 43. (doi:10.1095/biolreprod.113.109058)

Van Blerkom J, Davis PW \& Lee J 1995 ATP content of human oocytes and developmental potential and outcome after in-vitro fertilization and embryo transfer. Human Reproduction 10 415-424.

Van Hoeck V, Sturmey RG, Bermejo-Alvarez P, Rizos D, Gutierrez-Adan A, Leese HJ, Bols PE \& Leroy JL 2011 Elevated non-esterified fatty acid concentrations during bovine oocyte maturation compromise early embryo physiology. PLoS ONE 6 e23183. (doi:10.1371/journal.pone.0023183)

Van Hoeck V, Leroy JL, Arias Alvarez M, Rizos D, Gutierrez-Adan A, Schnorbusch K, Bols PE, Leese HJ \& Sturmey RG 2013 Oocyte developmental failure in response to elevated nonesterified fatty acid concentrations: mechanistic insights. Reproduction 145 33-44. (doi:10.1530/REP-12-0174)

Volpe A, Coukos G, Uccelli E, Droghini F, Adamo R \& Artini PG 1991 Follicular fluid lipoproteins in preovulatory period and their relationship with follicular maturation and progesterone production by human granulosa-luteal cells in vivo and in vitro. Journal of Endocrinological Investigation 14 737-742. (doi:10.1007/BF03347906)

Von Wald T, Monisova Y, Hacker MR, Yoo SW, Penzias AS, Reindollar RR \& Usheva A 2010 Age-related variations in follicular apolipoproteins may influence human oocyte maturation and fertility potential. Fertility and Sterility 93 2354-2361. (doi:10.1016/j.fertnstert.2008.12.129)

Wade RL, Van Andel RA, Rice SG, Banka CL \& Dyer CA 2002 Hepatic lipase deficiency attenuates mouse ovarian progesterone production leading to decreased ovulation and reduced litter size. Biology of Reproduction 66 1076-1082. (doi:10.1095/biolreprod66.4.1076)

Wakefield SL, Lane M, Schulz SJ, Hebart ML, Thompson JG \& Mitchell M 2008 Maternal supply of omega-3 polyunsaturated fatty acids alter mechanisms involved in oocyte and early embryo development in the mouse. American Journal of Physiology. Endocrinology and Metabolism 294 E425-E434. (doi:10.1152/ajpendo.00409.2007)

Wallace M, Cottell E, Gibney MJ, McAuliffe FM, Wingfield M \& Brennan L 2012 An investigation into the relationship between the metabolic profile of follicular fluid, oocyte developmental potential, and implantation outcome. Fertility and Sterility 97 1078.e1071-1084.e1078. (doi:10.1016/j.fertnstert.2012.01.122)

Wonnacott KE, Kwong WY, Hughes J, Salter AM, Lea RG, Garnsworthy PC \& Sinclair KD 2010 Dietary omega-3 and -6 polyunsaturated fatty acids affect the composition and development of sheep granulosa cells, oocytes and embryos. Reproduction 139 57-69. (doi:10.1530/REP-09-0219)

Wood BR, Chernenko T, Matthaus C, Diem M, Chong C, Bernhard U, Jene C, Brandli AA, McNaughton D, Tobin MJ et al. 2008 Shedding new light on the molecular architecture of oocytes using a combination of synchrotron Fourier transform-infrared and Raman spectroscopic mapping. Analytical Chemistry 80 9065-9072. (doi:10.1021/ac8015483)

Wu LL, Dunning KR, Yang X, Russell DL, Lane M, Norman RJ \& Robker RL 2010 High-fat diet causes lipotoxicity responses in cumulus-oocyte complexes and decreased fertilization rates. Endocrinology 151 5438-5445. (doi:10.1210/en.2010-0551)
Wu GQ, Jia BY, Li JJ, Fu XW, Zhou GB, Hou YP \& Zhu SE 2011 L-carnitine enhances oocyte maturation and development of parthenogenetic embryos in pigs. Theriogenology 76 785-793. (doi:10.1016/j.theriogenology.2011.04.011)

Wu LL, Russell DL, Norman RJ \& Robker RL 2012 Endoplasmic reticulum (ER) stress in cumulus-oocyte complexes impairs pentraxin-3 secretion, mitochondrial membrane potential (DeltaPsi m), and embryo development. Molecular Endocrinology 26 562-573. (doi:10.1210/me. 2011-1362)

Yang X, Dunning KR, Wu LL, Hickey TE, Norman RJ, Russell DL, Liang X \& Robker RL 2010 Identification of perilipin-2 as a lipid droplet protein regulated in oocytes during maturation. Reproduction, Fertility, and Development 22 1262-1271. (doi:10.1071/RD10091)

Yang X, Wu LL, Chura LR, Liang X, Lane M, Norman RJ \& Robker RL 2012 Exposure to lipid-rich follicular fluid is associated with endoplasmic reticulum stress and impaired oocyte maturation in cumulus-oocyte complexes. Fertility and Sterility 97 1438-1443. (doi:10.1016/j.fertnstert.2012.02.034)

Yazigi RA, Chi MM, Mastrogiannis DS, Strickler RC, Yang VC \& Lowry OH 1993 Enzyme activities and maturation in unstimulated and exogenous gonadotropin-stimulated human oocytes. American Journal of Physiology 264 C951-C955.

Yesilaltay A, Morales MG, Amigo L, Zanlungo S, Rigotti A, Karackattu SL, Donahee MH, Kozarsky KF \& Krieger M 2006 Effects of hepatic expression of the high-density lipoprotein receptor SR-BI on lipoprotein metabolism and female fertility. Endocrinology 147 1577-1588. (doi:10.1210/en.2005-1286)

You J, Lee J, Hyun SH \& Lee E 2012 L-carnitine treatment during oocyte maturation improves in vitro development of cloned pig embryos by influencing intracellular glutathione synthesis and embryonic gene expression. Theriogenology 78 235-243. (doi:10.1016/j.theriogenology.2012.02.027)

Yuan Y, Ida JM, Paczkowski M \& Krisher RL 2011 Identification of developmental competence-related genes in mature porcine oocytes. Molecular Reproduction and Development 78 565-575. (doi:10.1002/ mrd.21351)

Zachut M, Dekel I, Lehrer H, Arieli A, Arav A, Livshitz L, Yakoby S \& Moallem U 2010 Effects of dietary fats differing in n-6:n-3 ratio fed to high-yielding dairy cows on fatty acid composition of ovarian compartments, follicular status, and oocyte quality. Journal of Dairy Science 93 529-545. (doi:10.3168/jds.2009-2167)

Zamboni L \& Mastroianni L Jr 1966 Electron microscopic studies on rabbit ova: I. The follicular oocyte. Journal of Ultrastructure Research 14 95-117. (doi:10.1016/S0022-5320(66)80038-2)

Zeron Y, Ocheretny A, Kedar O, Borochov A, Sklan D \& Arav A 2001 Seasonal changes in bovine fertility: relation to developmental competence of oocytes, membrane properties and fatty acid composition of follicles. Reproduction 121 447-454. (doi:10.1530/rep.0.1210447)

Zeron Y, Sklan D \& Arav A 2002 Effect of polyunsaturated fatty acid supplementation on biophysical parameters and chilling sensitivity of ewe oocytes. Molecular Reproduction and Development 61 271-278. (doi:10.1002/mrd.1156)

Zhang W, Yi K, Yan H \& Zhou X 2012 Advances on in vitro production and cryopreservation of porcine embryos. Animal Reproduction Science 132 115-122. (doi:10.1016/j.anireprosci.2012.05.008)

Received 11 June 2013

First decision 7 August 2013

Revised manuscript received 16 April 2014

Accepted 17 April 2014 